\title{
Transparent hybrid polymer stamp copies with sub-50-nm resolution for thermal and UV-nanoimprint lithography
}

\author{
Helmut Schift, ${ }^{\text {a) }}$ Christian Spreu, ${ }^{\text {b) }}$ Menouer Saidani, ${ }^{\mathrm{c})}$ Martin Bednarzik, ${ }^{\mathrm{d})}$ and \\ Jens Gobrecht ${ }^{\mathrm{e})}$ \\ Laboratory for Micro- and Nanotechnology, Paul Scherrer Institut, 5232 Villigen PSI, Switzerland \\ Anna Klukowska, ${ }^{\text {() }}$ Freimut Reuther, ${ }^{\text {g) }}$ and Gabi Gruetzner ${ }^{\text {h) }}$ \\ Micro Resist Technology GmbH, Koepenicker Str. 325, 12555 Berlin, Germany \\ Harun H. Solak ${ }^{\mathrm{i})}$ \\ Eulitha AG, 5232 Villigen PSI, Switzerland
}

(Received 30 June 2009; accepted 21 September 2009; published 3 December 2009)

\begin{abstract}
The organic-inorganic hybrid polymer Ormostamp was successfully used for the fabrication of inexpensive, transparent working stamps to be used in nanoimprint lithography. The stamps were produced from different masters by casting and UV exposure of a viscous precursor. The cured hybrid stamp with the replicated surface relief was imprinted into several thermoplastic materials with up to $180{ }^{\circ} \mathrm{C}$ imprint temperature. In this article the authors show the effect of the imprint temperature on the structural fidelity. By using combined thermal and UV-nanoimprint lithography at $110{ }^{\circ} \mathrm{C}$ imprint temperature, a resolution down to $35 \mathrm{~nm}$ is demonstrated. They also investigated deterioration effects due to plasma treatment to simulate the effect of multiple recoating steps.

(C) 2009 American Vacuum Society. [DOI: 10.1116/1.3250207]
\end{abstract}

\section{INTRODUCTION}

In nanoimprint lithography (NIL) one of the critical issues is the fabrication of working stamps in sufficient quality and quantity. Stamp copying has not only become a means to enhance the lifetime of the original but also to reduce the risk of contamination and damage. ${ }^{1}$ Recently a novel organicinorganic hybrid polymer system was successfully used for the fabrication of NIL working stamps and commercialized under the name Ormostamp ${ }^{\circledR}$. The UV-curable hybrid polymer offers, besides high transparency, high thermal stability, and can therefore be used for UV-NIL and thermal NIL (TNIL), as well as for combined processes (TUV-NIL). ${ }^{2,3}$ Thus, transparent stamps can be fabricated by combining the structured surface layer in Ormostamp and a substrate with appropriate mechanical and optical properties.

Because of the high silicon content, the stamp surface can be permanently coated with fluorinated silane based antisticking layers (ASLs), which is a large asset in contrast to the polymer stamps used until now. ${ }^{4}$ To comply with the requirements for high resolution and structural fidelity, the oxygen plasma step needed for the surface activation prior to silane coating is considered as particularly crucial. The organic component in the cured hybrid material is susceptible to the oxygen treatment which may lead to deterioration of

\footnotetext{
${ }^{a)}$ Electronic mail: helmut.schift@psi.ch

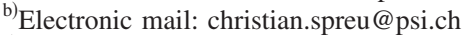

${ }^{c)}$ Electronic mail: menouer.saidani@psi.ch

d)Electronic mail: martin.bednarzik@psi.ch

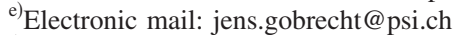

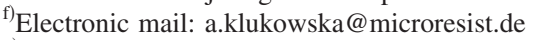

${ }^{g}$ Electronic mail: f.reuther@microresist.de

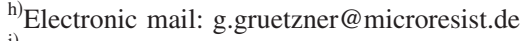

${ }^{i)}$ Electronic mail: harun.solak@psi.ch
}

surface hardness and loss of structural fidelity. We have now investigated the material in terms of different requirements. We have fabricated stamps with high resolution by using our large area, narrow band UV-NIL setup from different masters. We have coated it with a chemical vapor deposition based ASL coating process and varied plasma treating conditions to investigate the deterioration of small structures. We have made imprints in different materials under various process conditions. These investigations go further then those presented in Ref. 5 and aim to show the current limitation of the daughter stamp fabrication for thermal molding processes. Using this, we will be able to determine which processes are most suited for the use of these inexpensive daughter stamps.

\section{EXPERIMENT}

Ormostamp is a novel stamp material system based on an UV-curable inorganic-organic hybrid polymer with $i$-line characteristics. It can be spin coated or cast, depending on the thickness needed. With its high sensitivity around 365 $\mathrm{nm}$, it can be exposed with the common broadband emission spectrum of $\mathrm{Hg}$ lamps in mask aligners, but also with narrow band UV-light emitting diode devices as implemented in our Jenoptik HEX UV-NIL module. Because exposure in UVNIL is done through transparent stamps or substrates, a high UV-transmission is necessary both for the structured top layer as well as for the substrate. As has been shown in Ref. 2, the high UV transparency in Ormostamp is preserved after thermal treatment, i.e., $90 \%$ transparency at $350 \mathrm{~nm}$ of a 200 $\mathrm{nm}$ thick film after processing at $270{ }^{\circ} \mathrm{C}$. Furthermore a thermal expansion coefficient adapted to silicon for thermal imprint processes is needed. Borofloat ${ }^{\circledR} 33$, a borosilicate glass from Schott AG with excellent UV transparency and heat 


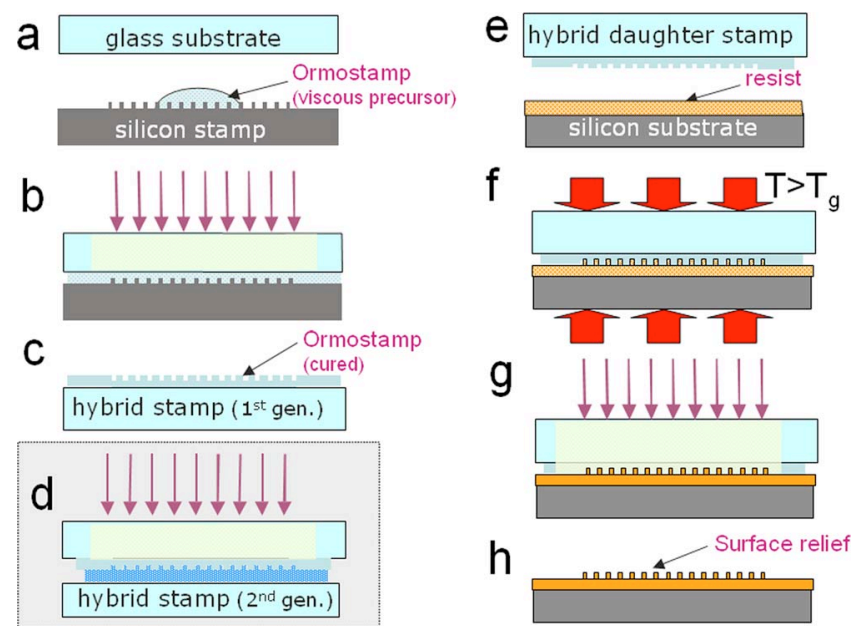

FIG. 1. (Color online) Process route for fabrication of hybrid daughter stamps and replication in thermoplastic material: [(a)-(c)] Fabrication of first generation daughter stamp from silicon master (zeroth generation), (d) optional copying of second generation daughter stamp, [(e)-(h)] combined thermal and UV-NIL in spin coated resist.

expansion adapted to silicon, shows the necessary qualities for TUV-NIL processes. As Pyrex ${ }^{\circledR}$ from Corning it is not only highly suitable for anodic bonding but also serves well as an inexpensive substitute for quartz substrates for the fabrication of hybrid stamps.

As a working stamp we generated a replica in Ormostamp, activated it in a short oxygen plasma step and coated it with ASL [Figs. 1(a)-1(c)]. Alternatively, if the tone of the original relief (zeroth generation master) needs to be preserved, a two-step process can be applied, i.e., a first generation intermediate replica can be generated by UV-NIL in Ormostamp or by hot embossing a polycarbonate foil before the replicated pattern is copied into the hybrid polymer (second generation replica) [Fig. 1(d)]. Prior to casting, the transparent glass substrate was cleaned in $\mathrm{H}_{2} \mathrm{O}_{2}: \mathrm{H}_{2} \mathrm{SO}_{4}$ (1:2) Caros etch for $10 \mathrm{~min}$ at $90{ }^{\circ} \mathrm{C}$, rinsed in de-ionized water, dried with nitrogen, and activated in $\mathrm{O}_{2}$-plasma for $10 \mathrm{~min}$. Afterward it was spin coated with a $100 \mathrm{~nm}$ thick film of adhesion promoter Ormoprime08 from Micro Resist Technology. The fabrication of the high resolution originals (masters) was done by extreme ultraviolet -interference lithography, as described in Ref. 6. Using this technique, periodic structures on relatively large areas can be generated with high resolution of down to $11 \mathrm{~nm}$. They are now available from Eulitha GmbH. For our experiments we choose stamps with multiple $0.5 \times 1 \mathrm{~mm}^{2}$ areas of period $76 \mathrm{~nm}$, linewidth of $20 \mathrm{~nm}$, and $47 \mathrm{~nm}$ depth made from direct hydrogen silsesquioxane (HSQ) pattern transfer into Si by reactive ion etching (RIE) (see Fig. 2). After dispensing of a defined quantity of the viscous Ormostamp precursor on a master stamp, the material drop was covered with the glass substrate and spread to a film, while the air was squeezed out from the gap between glass and stamp. Thus, a moderate thickness of Ormostamp was generated, which in our case was chosen between 30 and $50 \mu \mathrm{m}$. The imprint was done at $300 \mathrm{~N}$ at room temperature. In contrast to the broadband exposure, ${ }^{2}$ a narrow band expo-

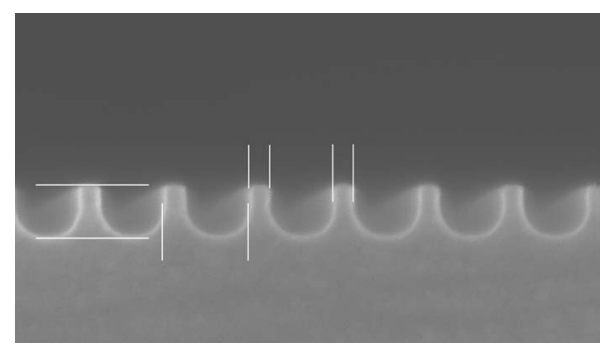

FIG. 2. Scanning electron microscopy micrographs from cross sections of RIE etched master stamp with $47 \mathrm{~nm}$ depth, period of $76 \mathrm{~nm}$, linewidth of $20 \mathrm{~nm}$, and $\sim 10 \mathrm{~nm}$ HSQ resist left after etching (initial thickness $60 \mathrm{~nm}$ ).

sure of our Jenoptik HEX UV-module (10 nm at $365 \mathrm{~nm}$ ) was used, with maximum intensity $I=2.8 \mathrm{~mW} / \mathrm{cm}^{2}$ in continuous mode. Because of the high sensitivity in the $i$-line range, the exposure time can be a few seconds, in contrast to the broadband exposure with maximum intensity $I$ $=1800 \mathrm{~mW} / \mathrm{cm}^{2}$ (measured at $365 \mathrm{~nm}$ ) for common pulsed systems. However, to assure full cross-linking, in these experiments, a relatively high exposure dose of $600 \mathrm{~mJ} / \mathrm{cm}^{2}$ was chosen. After exposure and demolding, the film was hardened in a postexposure bake (PEB) at $130{ }^{\circ} \mathrm{C}$ for 30 min. An antisticking coating with $\mathrm{F}_{13} \mathrm{TCS}$ was applied from the gas phase in vacuum ${ }^{4}$ at room temperature. To activate silanol groups for covalent binding of silanes, prior to ASL coating an oxygen plasma flash is used. In contrast to our standard process, where $1-2 \mathrm{~min}$ at $20 \mathrm{~W}$ is chosen, here we need to reduce this time to a minimum, i.e., around $30 \mathrm{~s}$, to reduce any possible deterioration. This is considered as sufficient.

For the imprint into thermoplastic materials [see Figs. $1(\mathrm{e})-1(\mathrm{~h})$ ], we chose three different materials from Micro Resist Technology, mr-NIL 6000.3, mr-I 7030 E, and 8030 E with a glass transition temperatures $T_{g}$ of 40,70 , and $115{ }^{\circ} \mathrm{C}$ and appropriate imprint temperatures $T_{\text {imprint }}$ of 110,140 , and $180{ }^{\circ} \mathrm{C}$, respectively (see Table I). In contrast to the purely thermoplastic materials, mr-NIL 6000.3 is designed for TUVNIL. We choose a process, where exposure is done after molding is complete, but before the stamp is detached from the substrate. All materials were spin coated to a thickness of $300 \mathrm{~nm}$ on standard $100 \mathrm{~mm}$ Si substrates, imprinted at 5-10 $\mathrm{kN}$ for $20 \mathrm{~min}$. Demolding temperature $T_{\text {demold }}$ was chosen to be at $30{ }^{\circ} \mathrm{C}$. For mr-NIL 6000.3, only the bottom plate was heated, while the exposure tool at the top stamper was kept at room temperature. As with Ormostamp, the dose of $600 \mathrm{~mJ} / \mathrm{cm}^{2}$ was chosen with $I=2.8 \mathrm{~mW} / \mathrm{cm}^{2}$ at $365 \mathrm{~nm}$. No PEB is needed.

For the investigation of the effect of long $\mathrm{O}_{2}$-plasma treatment, the stamps were treated in an Oxford Plasmalab 100 RIE using 20 SCCM (SCCM denotes cubic centimeter per minute at STP) $\mathrm{O}_{2}, 20 \mathrm{~W}$ at 20 mtorr. For surface activation we used 5 and $10 \mathrm{~min}$, which is $10-20$ times more than the $30 \mathrm{~s}$ for one process. 
TABLE I. Comparison of different thermoplastic materials replicated with Ormostamp molds.

\begin{tabular}{|c|c|c|c|c|c|}
\hline Polymer/resist & Process & $\begin{array}{c}\text { Glass transition } \\
\text { temperature } T_{g} \\
\left({ }^{\circ} \mathrm{C}\right)\end{array}$ & $\begin{array}{c}\text { Force } F \\
\quad(\mathrm{kN})\end{array}$ & $\begin{array}{l}\text { Time } t \\
(\mathrm{~min})\end{array}$ & $\begin{array}{c}\text { Press temperature } \\
T_{\text {top }} / T_{\text {bottom }} \\
\left({ }^{\circ} \mathrm{C}\right)\end{array}$ \\
\hline
\end{tabular}

\begin{tabular}{|c|c|c|c|c|c|}
\hline \multicolumn{6}{|c|}{ Imprint from Si master (zeroth generation into an Ormostamp replica (first generation) } \\
\hline Ormostamp & UV-NIL & - & 0.3 & 2 & RT $20 / 20$ \\
\hline \multicolumn{6}{|c|}{ Imprint with Ormostamp replica (first generation) into polymer replica (second generation) } \\
\hline mr-NIL 6000.3 & TUV-NIL & 40 & 5 & 20 & $20 / 110$ \\
\hline mr-I 7030 & T-NIL & 70 & 10 & 20 & $140 / 140$ \\
\hline mr-I 8030 & T-NIL & 115 & 10 & 20 & $180 / 180$ \\
\hline
\end{tabular}

\section{RESULTS}

The Ormostamp replica was used as a working stamp for NIL (see Fig. 3). Faithful replication of the stamp structures is achieved using the TUV-NIL process at an imprint temperature of $T_{\text {imprint }} 110^{\circ}$. The $35 \mathrm{~nm}$ half-pitch structures with an aspect ration of 1 are clearly replicated and show that the hardness of the Ormostamp stamp material is sufficient at process parameters of $5 \mathrm{kN}$ force (on $100 \mathrm{~mm}$ wafers), 20 min imprint time, and elevated temperature. In contrast to

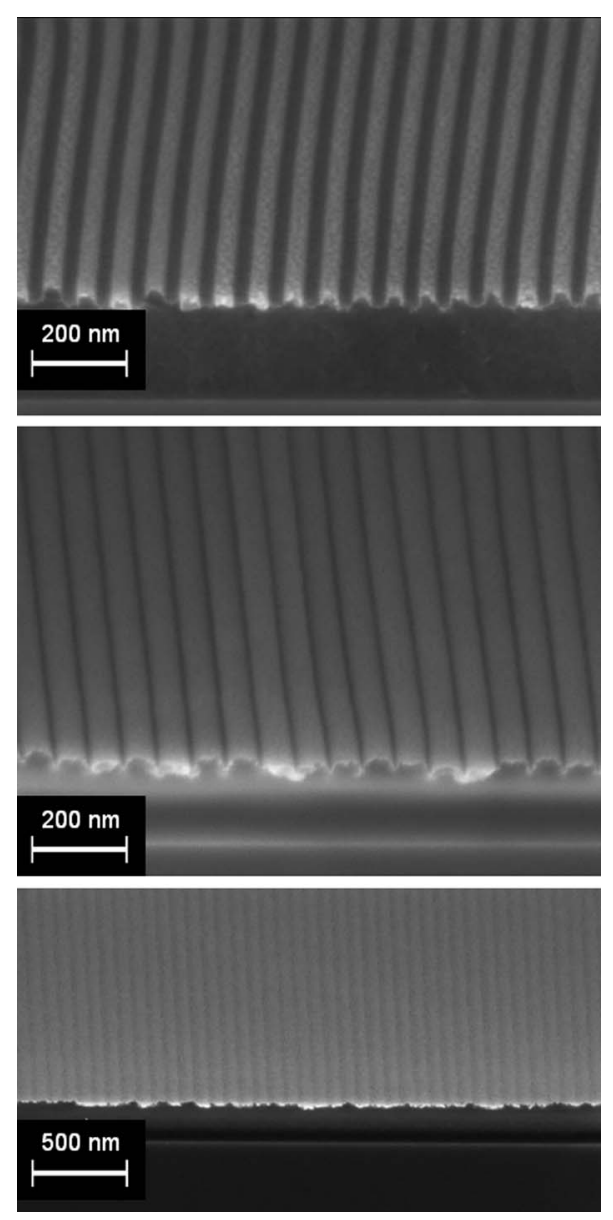

FIG. 3. Imprints of $35 \mathrm{~nm}$ half-pitch structures into different thermoplastic resists: structures in mr-NIL 6000.3 (top) are well replicated, in mr-I 7030 (center) they are slightly rounded, and in mr-I 8030 (bottom) they are poorly replicated. isolated small structures (e.g., pillars), where a residual elasticity of the material was found to be a disadvantage, the large grating of $0.5 \times 1 \mathrm{~mm}^{2}$ proved to be well suitable for replication. The temperature is well below the maximum imprint temperature of the UV-NIL module $\left(120^{\circ} \mathrm{C}\right)$ and makes it possible to define a standard process for mr-NIL 6000.3. This is currently not the case for T-NIL with the purely thermoplastic materials mr-I $7030 \mathrm{E}$ and $8030 \mathrm{E}$. While with mr-I $7030 \mathrm{E}$ only a slight structure rounding was observed, the structures were clearly smeared and ripped out by using mr-I $8030 \mathrm{E}$ (see Fig. 4). The main reason for this seems to be the elevated imprint temperatures of 140 and $180{ }^{\circ} \mathrm{C}$, respectively. However, better results were obtained with larger structures, i.e., pillar structures with $400 \mathrm{~nm}$ period, $200 \mathrm{~nm}$ diameter, and $400 \mathrm{~nm}$ height. This suggests that not only the imprint temperature but also the residual elasticity of the material at higher temperatures may be responsible for the deformation and ripping.
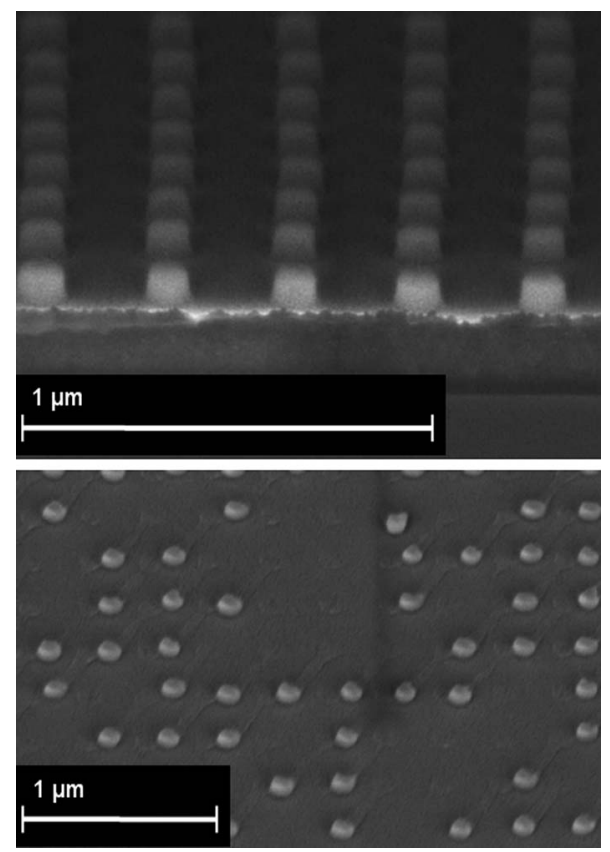

FIG. 4. Imprints of $100 \mathrm{~nm}$ diameter pillars into different thermoplastic resists: Structures in mr-NIL 6000.3 (top) are well replicated, in mr-I 8030 (bottom) only a part of the pillars are present (because they are either ripped away or the stamp were already filled from previous ripping). 
Apart from this, the experiments with long $\mathrm{O}_{2}$-plasma treatment in RIE showed a visible deterioration of the surface relief on the hybrid stamps. The $200 \mathrm{~nm}$ pillars were reduced by $100 \mathrm{~nm}$ in height and diameter. In contrast to this, small plasma treatments did not show any deterioration or structural changes.

\section{DISCUSSION}

Currently best results are achieved at processes with moderate temperatures (TUV-NIL). We are confident that by further optimizing the curing process for Ormostamp, process temperatures up to $140{ }^{\circ} \mathrm{C}$, as needed for mr-I $7030 \mathrm{E}$, can be achieved without deterioration of stamp nanostructures during imprint. This would mean that standard processes for purely thermoplastic materials (with useful process resistance properties for postprocessing in RIE or lift-off) can be developed. For the imprint at higher temperatures, as needed for polymethyl methacrylate or mr-I $8030 \mathrm{E}$, probably a further development of the Ormostamp material will be needed. The current results show, however, that the resolution capability of the hybrid material is suitable for many applications. In contrast to other viscous materials such as polydimethylsiloxane precursor, where the filling of structures smaller than $100 \mathrm{~nm}$ is difficult to achieve, there seems to be no visible restriction. ${ }^{7}$ Further experiments with new stamps will aim to show even higher resolutions and aspect ratios. Here stamps with a surface relief made from HSQ or harder sol-gel materials, which are processed at high temperatures to eliminate any elastic organic component, may be alternatives.

We further showed that short oxygen plasma steps can be used for surface activation without major surface erosion before the ASL layer is applied. However, the current maximum time of 5 min may be too short for more than ten coatings. The reduction in the structure diameter from 200 to $100 \mathrm{~nm}$ may be accompanied by a weakening of the material. This has to be investigated in future experiments. The current experiments do not show any effect of surface weakening for short exposures to plasma; therefore it can be anticipated that a few short plasma steps can be applied without modifying the shape, as well as the surface hardness and composition. For moderate imprint temperatures, several tens or hundreds of imprints may be possible.

\section{CONCLUSION}

As stated before, Ormostamp copies are inexpensive alternatives to electroplated stamps but are still restricted in lifetime and hardness. Their key advantage is that they can be cast from a multitude of originals, even replicas, e.g., in polycarbonate can be used. Therefore they enable to reduce cycle times for stamp copy fabrication and are a first step to replace expensive stamp originals by copies. Additional to this, by replication, opaque originals can be transferred into transparent copies. Furthermore by repeated copying, tone reversal is possible, which enables to copy an original into a set of stamp copies with different polarities. This is not only useful for process optimization in research but also for reducing cycle times in production by using the stamp polarity with better molding properties (e.g., pillar instead of hole arrays). In the future, several options will be evaluated, e.g., material combinations by using Ormostamp structures on prestructured substrates and on different substrate materials.

\section{ACKNOWLEDGMENTS}

The authors thank K. Vogelsang, A. Weber, and B. Haas (PSI Villigen); M. Altana (University of Applied Science Nordwestschweiz), F. Reuther, and G. Ungelenk (Jenoptik), for their help and valuable contributions. The research presented here was partially funded by the Swiss Federal Office for Science and Education in the framework of the ECfunded project NaPANIL (Contract No. NMP 214249).

${ }^{1}$ H. Schift, J. Vac. Sci. Technol. B 26, 458 (2008).

${ }^{2}$ A. Klukowska, M. Vogler, A. Kolander, F. Reuther, G. Gruetzner, M. Muehlberger, I. Bergmair, and R. Schoeftner, Proc. SPIE 6792, 67920J (2008).

${ }^{3}$ A. Klukowska, A. Kolander, I. Bergmair, M. Mühlberger, H. Leichtfried, F. Reuther, G. Grützner, and R. Schöftner, Microelectron. Eng. 86, 697 (2009).

${ }^{4}$ H. Schift, S. Saxer, S. Park, C. Padeste, U. Pieles, and J. Gobrecht, Nanotechnology 16, S171 (2005).

${ }^{5}$ M. Mühlberger et al., Microelectron. Eng. 86, 691 (2009).

${ }^{6}$ S. Park, H. Schift, H. H. Solak, and J. Gobrecht, J. Vac. Sci. Technol. B 22, 3246 (2004).

${ }^{7}$ N. Koo, U. Plachetka, M. Otto, J. Bolten, J.-H. Jeong, E.-S. Lee, and H. Kurz, Nanotechnology 19, 225304 (2008). 